\title{
Atmospheric correction issues for retrieving total suspended matter concentrations in inland waters using OLI/Landsat-8 image
}

\author{
Nariane Bernardo*, Fernanda Watanabe, Thanan Rodrigues, Enner Alcântara* \\ São Paulo State University, Department of Cartography, Roberto Simonsen Street, 305, Presidente Prudente, São Paulo 19060-900, Brazil
}

Received 8 June 2016; received in revised form 5 February 2017; accepted 8 February 2017

Available online 16 February 2017

\begin{abstract}
The atmospheric effects that influence on the signal registered by remote sensors might be minimized in order to provide reliable spectral information. In aquatic systems, the application of atmospheric correction aims to minimize such effects and avoid the under or overestimation of remote sensing reflectance $\left(R_{r s}\right)$. Accurately $R_{r s}$ provides better information about the state of aquatic system, it means, establishing the concentration of aquatic compounds more precisely. The aim of this study is to evaluate the outputs from several atmospheric correction methods (Dark Object Subtraction - DOS; Quick Atmospheric Correction - QUAC; Fast Line-of-sight Atmospheric Analysis of Hypercubes - FLAASH; Atmospheric Correction for OLI 'lite' - ACOLITE, and Provisional Landsat-8 Surface Reflectance Algorithm - L8SR) in order to investigate the suitability of $R_{r s}$ for estimating total suspended matter concentrations (TSM) in the Barra Bonita Hydroelectrical Reservoir. To establish TSM concentrations via atmospherically corrected Operational Land Imager (OLI) scene, the TSM retrieval model was calibrated and validated with in situ data. Thereby, the achieved results from TSM retrieval model application demonstrated that L8SR is able to provide the most suitable $R_{r s}$ values for green and red spectral bands, and consequently, the lowest TSM retrieval errors (Mean Absolute Percentage Error about $10 \%$ and $12 \%$, respectively). Retrieved $R_{r s}$ from near infrared band is still a challenge for all the tested algorithms.
\end{abstract}

(C) 2017 COSPAR. Published by Elsevier Ltd. All rights reserved.

Keywords: Atmospheric correction; Inland water; Water quality; Eutrophic environment

\section{Introduction}

Remotely sensed images present many advantages reported in literature, such as the spatial coverage and the temporal resolution to provide a long-term dataset of water quality monitoring (Baylei and Werdell, 2006; Neukermans et al., 2009; Bonansea et al., 2015; Zheng et al., 2015; Rotta et al., 2016). However, the use of remotely sensed information, represented by remote sensing reflectance $\left(R_{r s}\right.$, units in $\left.\mathrm{sr}^{-1}\right)$, depends on minimizing the influence of atmosphere compounds (gases and aerosols)

\footnotetext{
* Corresponding authors.

E-mail addresses: narianebernardo@gmail.com (N. Bernardo), enner@pq.cnpq.br (E. Alcântara).
}

(Chavez, 1988; Song et al., 2001; Tkacik et al., 2012; He and Chen, 2014; Lobo et al., 2014) that attenuate about $80 \%$ of remote-sensed signal (Roy et al., 2014). Atmospheric correction methods can be used to minimize the atmospheric effects, but an $R_{r s}$ over or underestimation can imply into a misunderstood of certain phenomena, in the other words, if the $R_{r s}$ quantities are not established accurately by the atmospheric correction, the estimates derived from $R_{r s}$ will be uncertain (Moses et al., 2012).

The atmospheric correction has been extensively discussed to focus on modeling the aerosol/gases contributions to the $R_{r s}$ from the signal registered by sensors (Chavez, 1988; Vermote and Vermeulen, 1999; Vermote et al., 2006, Ruddick et al., 2000; Moses et al., 2012; Goyens et al., 2013). Moreover, several studies have been 
conducted to evaluate what improvements are achieved when the atmospheric corrections are used in images over aquatic systems (Gong et al., 2008; Moses et al., 2012; Bonansea et al., 2015; Vanhellemont and Ruddick, 2015; Rotta et al., 2016). There are several atmospheric correction algorithms available (Berk et al., 1998; Adler-Golden et al., 1999; Matthew et al., 2000; Ruddick et al., 2000; Bernstein et al., 2013; Vanhellemont and Ruddick, 2015; Richter and Schläpfer, 2016) and code implemented in softwares of image processing, but there is no consensus about which one should be used for remote sensing of the water color. Consequently, the choice of the most suitable method is carried out based on reducing the atmospheric interference, evaluated according to least error and the matching between corrected image remote sensing reflectance $\left(R_{r s}\right)$ and 'truth ground' (Ruddick et al., 2000; Moses et al., 2009; Watanabe et al., 2015; Bernardo et al., 2015). However, will atmospheric correction methods convert the top-of-atmospheric reflectance $\left(R_{T O A}\right)$ into the suitable $R_{r s}$ to provide reliable information for aquatic system investigations? Nevertheless, the main question formulated in this study is: will the estimation of Total Suspended Matter (TSM), an indicator of water quality, based on preprocessed imagery data using different atmo- spheric correction algorithms provide similar results? Relied on it, this study aims to evaluate the reliability of atmospheric correction methods to provide suitable $R_{r s}$ for quantifying TSM concentrations in the Barra Bonita Hydroelectric Reservoir (BBHR). To address this issue, we establish an empirical TSM retrieval model using in situ measurements and evaluate the suitability of $R_{r s}$ from atmospherically corrected images by applying the empirical model to retrieve TSM concentrations. It is not the intention of this work to show which atmospheric correction algorithm is the best for water quality studies using remote sensing data, but rather to show the impact of selecting a specific algorithm instead of another one to develop remotely sensed data applications in inland waters.

\section{Methodology}

\subsection{Study area}

The damming of Tietê and Piracicaba Rivers formed the BBHR - the first of a series of reservoirs in cascade, located in São Paulo State, southeast region of Brazil (Fig. 1). The BBHR has a flooding area of approximately $310 \mathrm{~km}^{2}$, a mean depth of $10.2 \mathrm{~m}$, and a retention time that varies
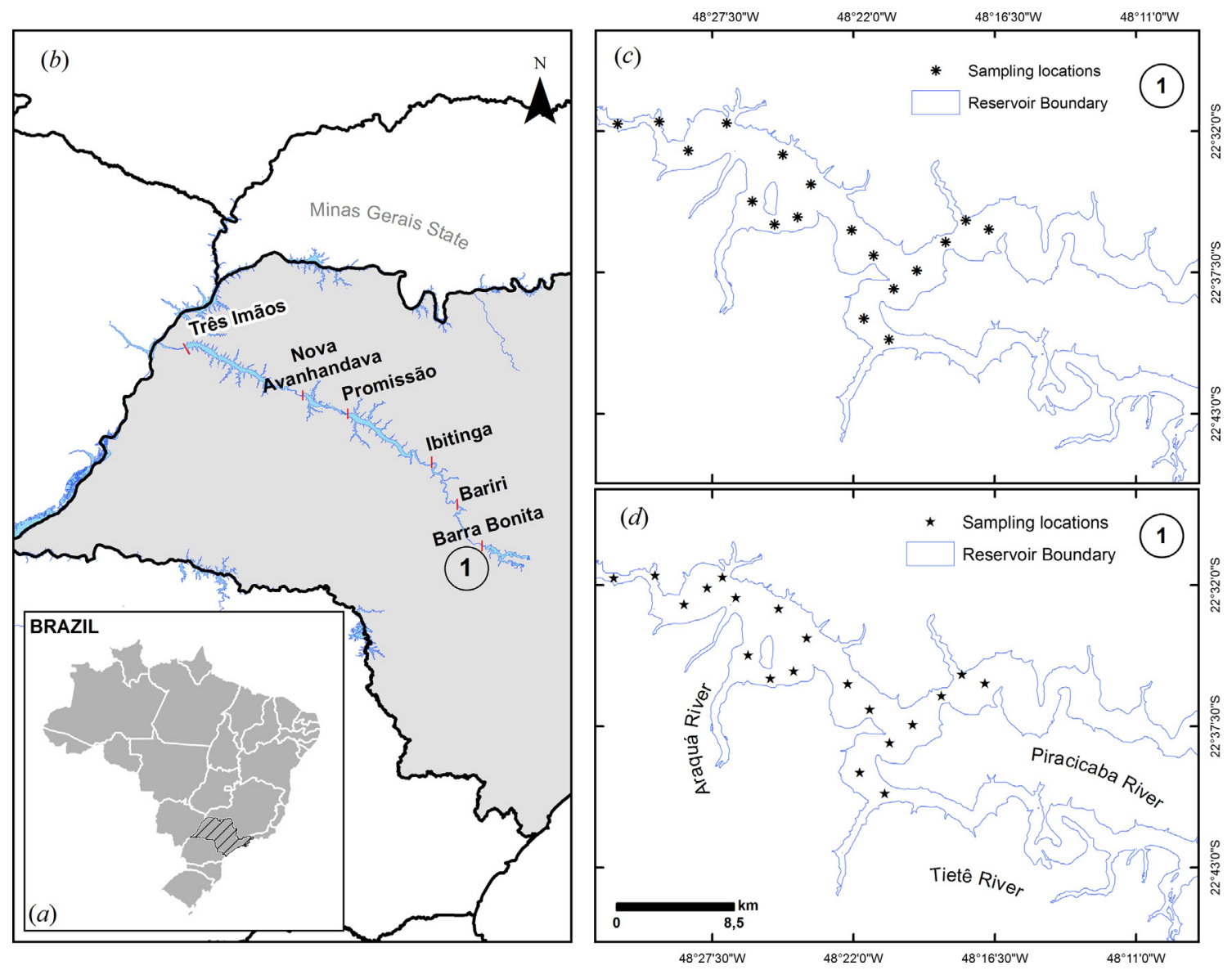

Fig. 1. Location of study area - (a) Brazil highlighting the State of Sao Paulo; (b) Tietê River and its cascade of reservoirs (from upstream to downstream: Barra Bonita, Bariri, Ibitinga, Promissão, Nova Avanhandava, and Três Irmãos) and number 1 shows the BBHR location in the cascading system, with the sampling stations collected in the (c) first $(n=18)$ and (d) second $(n=18)$ fieldworks, with 36 stations in total. 
from 30 days (Austral summer) to 180 days (Austral winter) because of rainy weather in such tropical area (Watanabe et al., 2015). Besides the electricity generation, the reservoir is part of the Tietê-Paraná waterway, which is used to transport the Brazilian agriculture production, and plays an important economic role such as fishery, leisure and water supply. However, the high reduction of fish specie diversity due to water contamination (Petesse et al., 2007) considering the studies that have indicated the BBHR as a eutrophic environment - high levels of nutrients and TSM in its 114 tributaries (Tundisi et al., 2008; Smith et al., 2014).

\subsection{Fieldwork}

Two campaigns were carried out from 5 to 8 May 2014, and from 13 to 16 October 2014. The optically significant component (OSC, such as TSM and Chlorophyll- $a-\mathrm{Chl}-$ a) concentrations and other water quality variables were measured from in situ water samples collected just below the water surface at each sampling location (see Fig. 1 for site locations, $n=18$ from each campaign). The TSM concentrations were determined following APHA (1998) protocol. The pre-ignited Whatman GF/F filter (GE Healthcare, Little Chalfont, UK), with $47 \mathrm{~mm}$ diameter and $0.7 \mu \mathrm{m}$ nominal pore size, were weighted before $\left(P_{0}\right)$ and after the filtration/drying process $\left(P_{1}\right)$ in an analytical balance. The drying process was made in an oven for $12 \mathrm{~h}$ at $105^{\circ} \mathrm{C}$. The difference between $P_{0}$ and $P_{1}$ was divided by the filtered water volume, which results to the TSM concentration in ( $\left.\mathrm{mg} \mathrm{L}^{-1}\right)$. The Chl- $a$ concentration was determined based on acetone extraction (Golterman, 1975). The Chl- $a$ pigment was extracted from Whatman GF/F glass filter ( $47 \mathrm{~mm}$ diameter and $0.7 \mu \mathrm{m}$ pore size) with maceration using a $90 \%$ acetone solution. The macerated samples were centrifuged and the absorbance at $663 \mathrm{~nm}$ and $750 \mathrm{~nm}$ from each sample was read using 700Plus UV-VIS spectrophotometer (FEMTO, São Paulo, Brazil).

Water quality measurements were taken from in situ samples using portable digital instruments. Turbidity (in Nephelometric Turbidity Unit - NTU, Romania, USA) were measured in triplicate using a HI 98703 Turbidity Meter (Hanna Instruments, Woonsocket, USA), which was calibrated in the beginning of each day campaign using the standard solutions (1 NTU, 10 NTU, 75 NTU, 100 NTU, 750 NTU). Dissolved Oxygen (DO) were measured (in $\mathrm{m} \mathrm{L} \mathrm{L}^{-1}$ ) using a HI9146 dissolved oxygen meter (Hanna Instruments, Woonsocket, USA), which was auto calibrated before each day campaign. The Secchi Disk depth was measured using a standard black-white disk of $30 \mathrm{~cm}$ diameter with a measuring rope that was lowered into the water until the disk disappears. The marked line intersected by the water surface indicated the depth of water clarity, i.e., the Secchi Disk depth.

Simultaneously, in situ radiometric measurements were made using three TriOS hyperspectral radiometers: two ARC-VIS sensors with a $7^{\circ}$ field-of-view (FOV) in order to measure radiance, and one ACC-VIS sensor with a cosine collector to measure irradiance. ARC and ACC sensors have $3.3 \mathrm{~nm}$ spectral sampling, working in a spectral range of 320-950 $\mathrm{nm}$, with an integration time of $4 \mathrm{~ms}$ to $8 \mathrm{~s}$ (TriOS, 2009, Rastede, Germany). Radiances (total radiance $-L_{t}$; and diffuse or incident sky radiance $-L_{s k y}$, both in $\mathrm{W} \mathrm{m}^{-2} \mathrm{sr}^{-1} \mathrm{~nm}^{-1}$ ) and downwelling irradiance $\left(E_{d}\right.$, units in $\left.\mathrm{W} \mathrm{m}^{-2} \mathrm{~nm}^{-1}\right)$ were measured above water $\left(0^{+}\right)$, and the radiances were collected in an azimuth angle of $90^{\circ}$ in order to minimize specular reflection and boat shadowing (Mobley, 1999). Hyperspectral measurements were used to calculate the above water $R_{r s}$ (Mobley, 1999), by using Eqs. (1a)-(1d).

$$
\begin{aligned}
& R_{r s}\left(\theta, \varphi, \lambda, 0^{+}\right)=\frac{L_{w}(\theta, \varphi, \lambda)}{E_{d}(\lambda)} \\
& L_{t}(\theta, \varphi, \lambda)=L_{r}(\theta, \varphi, \lambda)+L_{w}(\theta, \varphi, \lambda) \\
& L_{r}(\theta, \varphi, \lambda)=\rho \times L_{s k y}(\theta, \varphi, \lambda) \\
& R_{r s}\left(\theta, \varphi, \lambda, 0^{+}\right)=\frac{L_{t}\left(\theta, \varphi, \lambda, 0^{+}\right)-0.028 \times L_{s k y}\left(\theta, \varphi, \lambda, 0^{+}\right)}{E_{d}\left(\theta, \varphi, \lambda, 0^{+}\right)}
\end{aligned}
$$

where $\varphi$ is the azimuthal angle (in $90 \mathrm{deg}$ ); $\theta$ is the zenithal angle (of $40 \mathrm{deg}$ ); $\lambda$ is the wavelength (in $\mathrm{nm}$ ), and $0^{+}$indicates that radiance and irradiance measurements were acquired just above the water surface. The Eq. (1b) provides the water-leaving radiance $\left(L_{w}\right.$, in $\left.\mathrm{W} \mathrm{m}^{-2} \mathrm{sr}^{-1} \mathrm{~nm}^{-1}\right)$ given by the difference between $L_{t}$ and $L_{r} . L_{w}$ contains the real information from the volumetric radiance of water column, which carried information about composition and, consequently, water color. Nevertheless, we cannot measure $L_{w}$ directly by a sensor due to atmospheric effects. The measurement made by a sensor above water would sum up the signal from water $\left(L_{w}\right.$, signal from the inside water) and the part of the signal from sky radiance that reach the water surface, without penetration, and it is reflected into the FOV, called $L_{r}$ (in $\mathrm{W} \mathrm{m}^{-2} \mathrm{sr}^{-1} \mathrm{~nm}^{-1}$ ). The $L_{r}$ is represented in terms of incident sky radiance $\left(L_{s k y}\right)$, by the following relationship: $L_{r}=\rho \times L_{s k y}$ (Eq. (1c)), where $\rho$ is the proportional factor, which relates the $L_{\text {sky }}$ to the radiance from the sea surface that is actually measured by a sensor. The $\rho$ factor depends on direction, wavelength, wind speed, sky radiance distribution and FOV. The assumption of $\rho=0.028$ (Eq. (1d)) was done due to wind speed reported in the BBHR (less than $\left.5 \mathrm{~m} \mathrm{~s}^{-1}\right)$ and the geometry viewing of sensor $\left(\theta=40^{\circ}\right)$ (Mobley, 1999).

To simulate the $R_{r s}$ that would be recorded by the satellite sensor at each channel centered at wavelength $\lambda_{i}\left[R_{r s \_s}\left(\theta, \varphi, \lambda_{i}, 0^{+}\right)\right]$, the signal from in situ measurements was multiplied by the relative spectral function response (SFR, represented as $S(\lambda)$ ) of Operational Land Imager OLI, Barsi et al., 2014), as given below (Eq. (2)).

$R_{r s\lrcorner}\left(\theta, \varphi, \lambda_{i}, 0^{+}\right)=\frac{\sum_{\lambda} R_{r s}\left(\theta, \varphi, \lambda, 0^{+}\right) \times S(\lambda)}{\sum_{\lambda} S(\lambda)}$ 
where $S(\lambda)$ is the OLI spectral response function (Barsi et al., 2014), and $R_{r s s}\left(\theta, \varphi, \lambda_{i}, 0^{+}\right)$is the resampled $R_{r s}$ to the OLI spectral bands (Van der Meer, 1999). The $R_{r s_{S}}$ in the green (OLI3 - $561.4 \mathrm{~nm}$ ), red (OLI4 $654.6 \mathrm{~nm})$ and Near Infrared - NIR (OLI5 - $864.7 \mathrm{~nm})$ bands were used to evaluate the atmospheric correction methods as well as to calibrate and validate a bio-optical model for retrieving the TSM concentrations.

\subsection{OLI data}

The OLI sensor, launched on February 2013 to continue the Landsat Data Continuity Mission (LDCM), provides remote-sensed data for monitoring Earth system process and understanding the status and dynamics of the planet (Roy et al., 2014). Due to its medium spatial resolution $(30 \mathrm{~m})$, revisit time of 16 days and the five spectral bands in the visible-near infrared range, the potential of OLI data to estimate OSC concentrations in coastal and inland waters has been investigated (Vanhellemont and Ruddick, 2015; Wu et al., 2015; Bernardo et al., 2016). The OLI cloud-free image acquired on 13 October 2014 was downloaded from Earth Explorer at Level 1T with radiometric and geometric corrections (USGS, 2015a,b) and submitted to atmospheric correction application. The scale factors available on metadata file (Table 1) were used to convert the Digital Number into top-of-atmosphere radiance $\left(L_{T O A}\right)$ measurements for each band and the $L_{T O A}$ image was used as input of some tested atmospheric correction methods. All methods used as input the nadir OLI image, it means, with a roll angle near zero (information available on metadata file).

\subsection{Application of atmospheric correction algorithms}

Five atmospheric correction algorithms were tested: Dark Object Subtraction (DOS - Chavez, 1988), Quick Atmospheric Correction (QUAC - Bernstein, 2005), Fast Line-of-sight Atmospheric Analysis of Hypercubes (FLAASH - Adler-Golden et al., 1999), Atmospheric Correction for OLI 'lite' (ACOLITE - Vanhellemont and Ruddick, 2014), and Provisional Landsat-8 Surface Reflectance Algorithm (L8SR - USGS, 2015a,b). These models, divided in two categories - in-scene and model based atmospheric corrections (Hadjimitsis and Clayton, 2009), were selected because they are widely used in remote sensing of the water color (Moses et al., 2012; Ha et al., 2014;
Vanhellemont and Ruddick, 2015; Stratoulias et al., 2015). Moreover, the averaging of five atmospheric correction results was made to analyze whether a combined algorithm would improve the $R_{r s}$ and TSM estimates.

\subsubsection{In-scene atmospheric correction methods}

The atmospheric correction methods that rely on scene information, such DOS, ACOLITE and QUAC, can be called as In-Scene methods. DOS is based on image information and considers only the correction of the atmospheric additive scattering. Atmospheric absorption features and secondary scattering (such as skylight) are not included in this procedure (Chavez, 1988). The main idea is to find the darkest pixel in a spectral band with a non-zero top-of-atmosphere reflectance $\left(R_{T O A}\right)$, which has been registered by remote sensor. The darkest pixel has a high probability of showing a zero reflectance, however, due to atmospheric scattering, some energy is attributed to that pixel, which represents the quantity of scattering that occurs in the atmosphere. To minimize this effect, the value of $R_{T O A}$ from the darkest pixel in each band is subtracted from every pixel within the respective band, such as an offset. To find the lowest value in each OLI band in the BBHR environment and retrieve a measurement of the scattering effect, the histogram of $R_{T O A}$ from each OLI spectral band was analyzed and the lowest value with the highest frequency was used as offset. The $R_{T O A}$ bands were yielded from radiometric calibration using metadata file.

In turn, QUAC performs the equalization of the variance of image based on selected endmembers, which are those targets that can be represented by a unique spectrum from an available library collection (Bernstein et al., 2013). Three assumptions are also considered to perform QUAC correction: (1) the image must present more than 10 spectrally different pixels; (2) a standard deviation of reflectance from end-members pixels may be calculated and it is assumed as spectrally independent, and can be used to calculate the transmittance; and (3) there is a relevant number of dark pixels to calculate an invariant baseline assumed as a measurement of attenuation (scattering and absorption) and adjacency effect (Bernstein, 2005). QUAC was applied to the OLI image and any atmospheric parameter was required, allowing classify this process as a semiempirical method (Moses et al., 2012).

ACOLITE module was developed by the Royal Belgian Institute of Natural Sciences (RBINS), and allows process-

Table 1

OLI spectral bands and scale factors to convert digital numbers into $L_{T O A}$.

\begin{tabular}{llll}
\hline Index & Spectral band $(\lambda$ central, in $\mathrm{nm})$ & Additive factor & Multiplicative factor \\
\hline OLI1 & Coastal $\left(\lambda_{443.0 \mathrm{~nm}}\right)$ & 0.012613 & -63.06679 \\
OLI2 & Blue $\left(\lambda_{482.0} \mathrm{~nm}\right)$ & 0.012916 & -64.58116 \\
OLI3 & Green $\left(\lambda_{561.4 \mathrm{~nm}}\right)$ & 0.01902 & -59.51099 \\
OLI4 & Red $\left(\lambda_{654.6 \mathrm{~nm}}\right)$ & 0.010037 & -50.18302 \\
OLI5 & NIR $\left(\lambda_{864.7 \mathrm{~nm}}\right)$ & 0.0061419 & -30.70950 \\
\hline
\end{tabular}


ing OLI/L8 data quickly and easily, for inland, coastal and oceanic waters (Vanhellemont and Ruddick, 2015). ACOLITE computes the average values of solar irradiance (F0), Rayleigh optical thickness, ozone thickness, and water absorption $\left(a_{w}\right)$ based on the convolution of OLI relative SFR (Barsi et al., 2014). The assumptions and calculations are detailed in Vanhellemont and Ruddick (2015) that describes the equations used to compute and correct the aerosol and Rayleigh scattering effects. In ACOLITE did not correct the influence of foam and whitecaps on reflectance surface from aquatic systems, considering that the BBHR system did not present whitecaps during the fieldwork and foam effects were ignored due to its small contribution for the scattering effect.

The cropped OLI image in digital number, with boundaries established by the BBHR's watershed, was used as input in ACOLITE (version 20150701.1). The aerosol correction was made based on Short-Wave Infrared (SWIR) band, and the epsilon for identifying the aerosol type was calculated over sub-scene taking into account the ratio band of Rayleigh corrected reflectance. The Rayleigh correction was made using $0.5 \mathrm{~km}$ as ground elevation, which automatically recalculated the correction parameters such as the Rayleigh scale factor and the atmospheric pressure. The clouds were masked using the default parameterization considering SWIR-1 band (OLI6).

The aerosol correction using NIR band in ACOLITE was also tested, however, this option led to atmospheric overcorrection of the image, yielding negative outputs. The overcorrection is most likely associated with the high turbidity, which increases $R_{r s}$ values in the NIR spectral region, where it is expected values close to zero due to strong $a_{w}$ (Chavez, 1988; Vanhellemont and Ruddick, 2015).

\subsubsection{Model-based atmospheric correction methods}

Physical methods attempt to model the atmospheric effects by solving a radioactive transfer equation, such as FLAASH. FLAASH is an interface of MODTRAN (MODerate spectral resolution atmospheric TRANsmittance) (Adler-Golden et al., 1999), and its performance depends on input data, such as initial visibility, optical depth, aerosol type model, and water vapor amount (Moses et al., 2012). The FLAASH processing were applied to $L_{T O A}$ OLI image using a rural aerosol model (due to land cover surrounding BBHR's). The tropical atmospheric model and the aerosol retrieval method were computed using the Kaufman-Tanre settings, specifically the Overland-Alternate option that provides the aerosol content in atmosphere using the Coastal/SWIR band ratio, as recommended by ENVI (2009) when there is no actual measurement of atmospheric profile available. Each FLAASH's application has input parameters that were adopted based on geographic location, and viewing/illumination geometry. It is known that such assumptions can imply errors in estimating surface reflectances $\left(R_{S U P}\right)$. However, in situ measurements of atmospheric conditions were not made during the fieldwork and the adoption of the input parameters is a viable approach for correcting the image and starting the iterative process made by atmospheric correction algorithm (Moses et al., 2012).

L8SR product (USGS, 2015a,b) processed and made available by the United States Geological Survey (USGS) was also investigated. The USGS processing uses the MODIS CMA (Moderate Resolution Imaging Spectroradiometer - Climate Modeling Grid-Aerosol, Vermote et al., 2011) information as input data (Vermote et al., 2016). The L8SR product provides the $R_{S U P}$ image rescaled by a factor of 10,000 . Thereby, the BBHR's image was multiplied by 0.0001 to convert it into original $R_{S U P}$.

Each tested atmospheric algorithm, described in Sections 2.4.1 and 2.4.2, yielded $R_{S U P}$, then, $R_{S U P}$ image was converted into $R_{r s}$ image (Moses et al., 2012) through division by $\pi$.

\subsection{Assessment of atmospheric correction}

Atmospheric correction methods were applied to the OLI image (path/row 220/76) taken on 13 October 2014, because its acquisition date matches with the second fieldwork ( $n=6$ samples were gathered out in this day). Atmospheric correction results were assessed based on optical closure between the results from atmospheric correction methods and the $R_{r s s}\left(\theta, \varphi, \lambda_{i}, 0^{+}\right)$values from the pixel that matches with the geographic location used to sample the radiometric quantities and water quality parameters. In order to evaluate the results from each application, the coefficient of determination $\left(R^{2}\right)$, the Mean Absolute Percentage Error (MAPE - Eq. (3)) and bias (Eq. (4)) were calculated using $R_{r S_{s} s}$ as reference data ( $x_{\text {true }}$ ) to compare the results from atmospherically corrected (AC) OLI image $\left(x_{i}\right)$.

$$
\begin{aligned}
& \text { MAPE }=\frac{1}{n} \times \sum_{i=1}^{n}\left|\frac{x_{i}-x_{\text {true }}}{x_{\text {true }}}\right| \times 100 \\
& \operatorname{Bias}=\frac{1}{n} \times \sum_{i=1}^{n}\left(x_{i}-x_{\text {true }}\right)
\end{aligned}
$$

where $x_{i}$ is the estimated TSM concentration, and $x_{\text {true }}$ is the TSM concentration measured in situ, $i$ is the first and $n$ is the last sample used to validate the TSM retrieval model.

\subsection{TSM modeling development}

The TSM concentration estimates were made using empirical models. The adjustment and validation of TSM retrieval models were conducted using in situ measurements. The $R_{r s \_s}$ (Eq. (2)) and TSM concentrations from both fieldworks were randomly separated in two groups: (1) to calibrate the models with two-thirds of the sample number $(n=23)$; and (2) to validate the models with onethird of the sample number $(n=13)$. The models were 
made testing one-band and band ratios as index to retrieve TSM concentrations, and linear, quadratic and exponential as functions to fit the models.

The quality of the linear and non-linear regression models was evaluated based on $p$-value, coefficient of determination $\left(R^{2}\right)$, the Root Mean Squared Error (RMSE - Eq. (5), in $\mathrm{mg} \mathrm{L}^{-1}$ ), the normalized RMSE (nRMSE - Eq. (6), in \%), and Bias (Eq. (4), in $\mathrm{mg} \mathrm{L}^{-1}$ ), using in situ TSM measurements as reference. The error analysis allowed establishing whether TSM retrieval models were suitable to be applied to AC OLI image.

$\mathrm{RMSE}=\sqrt{\frac{\sum_{i=1}^{n}\left(x_{i}-x_{\text {true }}\right)^{2}}{n}}$

$\mathrm{nRMSE}=\frac{\mathrm{RMSE}}{\left(x_{\text {max }}^{\text {true }}-x_{\text {min }}^{\text {true }}\right)} \times 100$

where $x_{i}$ is the estimated TSM concentration, and $x_{\text {true }}$ is the TSM concentration measured in situ, $i$ is the estimation that varies from 1 to $n$, where $n$ is the sample number used to validate the TSM retrieval model.

\subsection{Effects of atmospheric correction on TSM estimates}

The adjusted bio-optical models were applied to each AC OLI image (acquired on 13 October 2014) and to the combined result (representing the average of the five tested atmospheric correction). The assessment of TSM retrieval errors was made by using MAPE (Eq. (3)), bias (Eq. (4)) and RMSE (Eq. (5)). Other effects such as systematic errors that can happen with in situ measurements and the effect of pixel size, errors of adjustment due to TSM retrieval model and the influence of viewing geometry during radiometric measurements that were treated as errors sources, were not considered in this study.

The error analysis (MAPE, bias and RMSE) made to evaluate the effects of atmospheric correction on TSM estimates considered the in situ TSM concentrations $(n=6$ of 18 samples from the second fieldwork collected during OLI overpass) as reference. The differences among MAPE and nRMSE results are the square used in RMSE equation (see Eqs. (3) and (5)), which provides more relevance for the high residuals than the mean used in MAPE.

\section{Results}

\subsection{BBHR water quality and radiometric features}

The BBHR showed high Chl- $a$ concentration, which characterizes the reservoir as a eutrophic environment (Watanabe et al., 2015). The statistics about measurements gathered out from the 1st and 2nd survey fieldworks are described in Table 2. There was an increase of TSM concentrations from the 1st to the 2 nd survey. Turbidity and Secchi Disk depth followed an expected behavior: the first was directly proportional to TSM concentrations and the

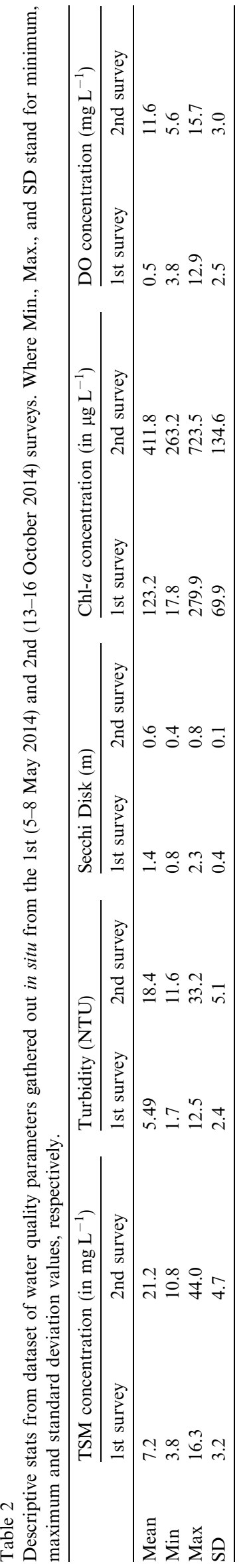


second was inversely proportional to TSM concentrations. Furthermore, the high Chl- $a$ concentration affected the DO, since planktons are a source of DO because of photosynthesis (Fondriest, 2013), as observed in Table 2.

The variability of the water quality parameters found between the two fieldworks modulates the $R_{r s}$ spectra collected in situ (Fig. 2a and c, for 1st and 2nd fieldworks, respectively). The main differences between both fieldworks can be observed, mostly in the visible range that is a interval very sensitive to phytoplankton pigments (Watanabe et al., 2015; Bernardo et al., 2015). The high absorption close to $620 \mathrm{~nm}$ can be associated with the phycocyanin, pigment presents in cyanobacteria that were dominated by Mycrosystis species in the BBHR (Dellamano-Oliveira et al., 2008). The high absorption of water and the high backscattering of Chl- $a$ nearly $710 \mathrm{~nm}$, produced the reflectance peak in both fieldworks (Kutser et al., 2016). Moreover, the peak present at $810 \mathrm{~nm}$ resulted from reflection of chlorophyll and organic matter combination (Rundquist et al., 1996).

The prominent reflectance peak near $550 \mathrm{~nm}$ observed in hyperspectral curves was maintained in resampled spectral curves (via Eq. (2)) for OLI bands (Fig. 2b and d). The shoulder about $470 \mathrm{~nm}$ due to high absorption of CDOM and Chl- $a$ was detected by the OLI2 spectral band, but the spectral features found in hyperspectral data between
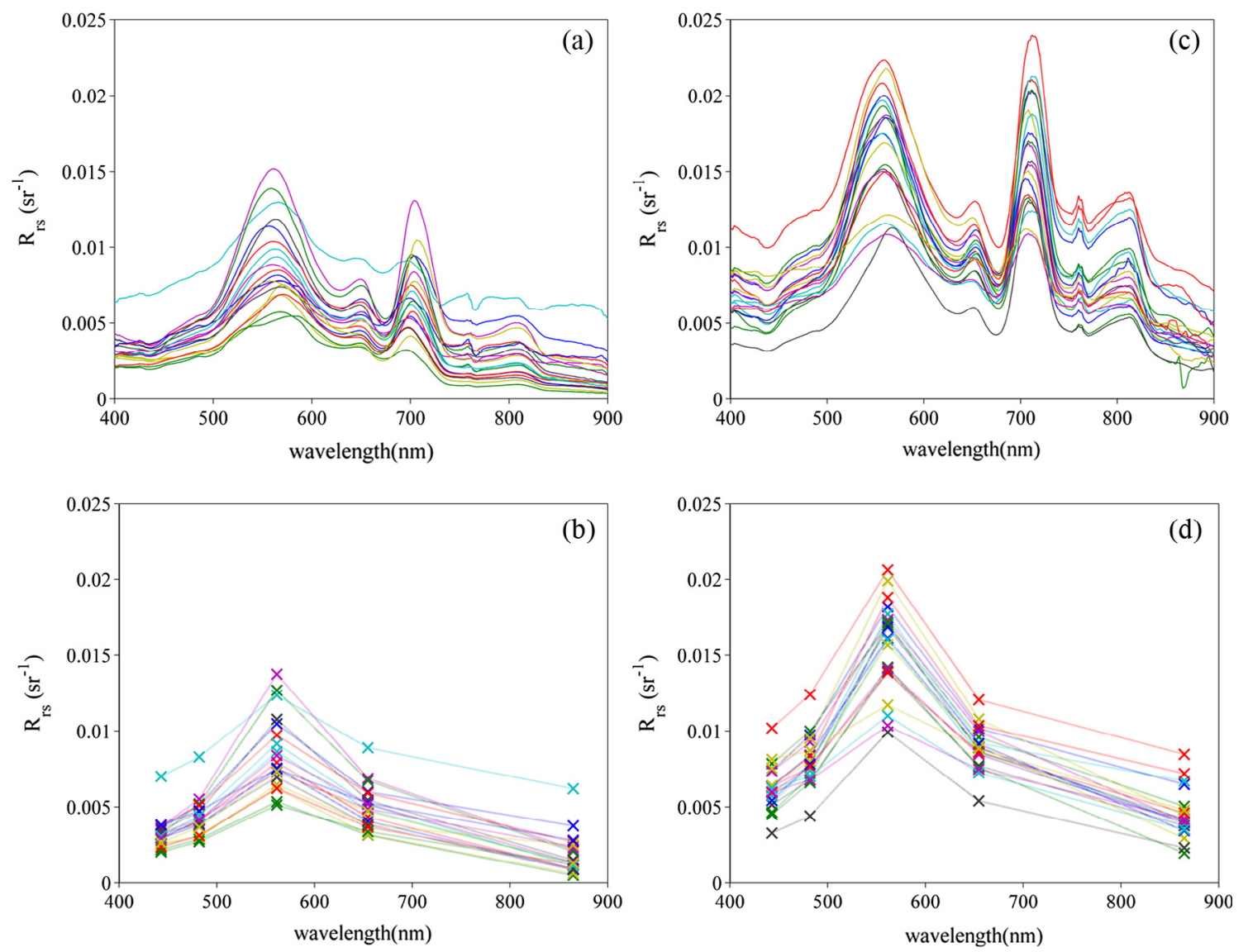

Fig. 2. Hyperspectral and resampling dataset from in situ measurements in the 1st (a and b) and 2nd fieldworks (c and d), respectively. 

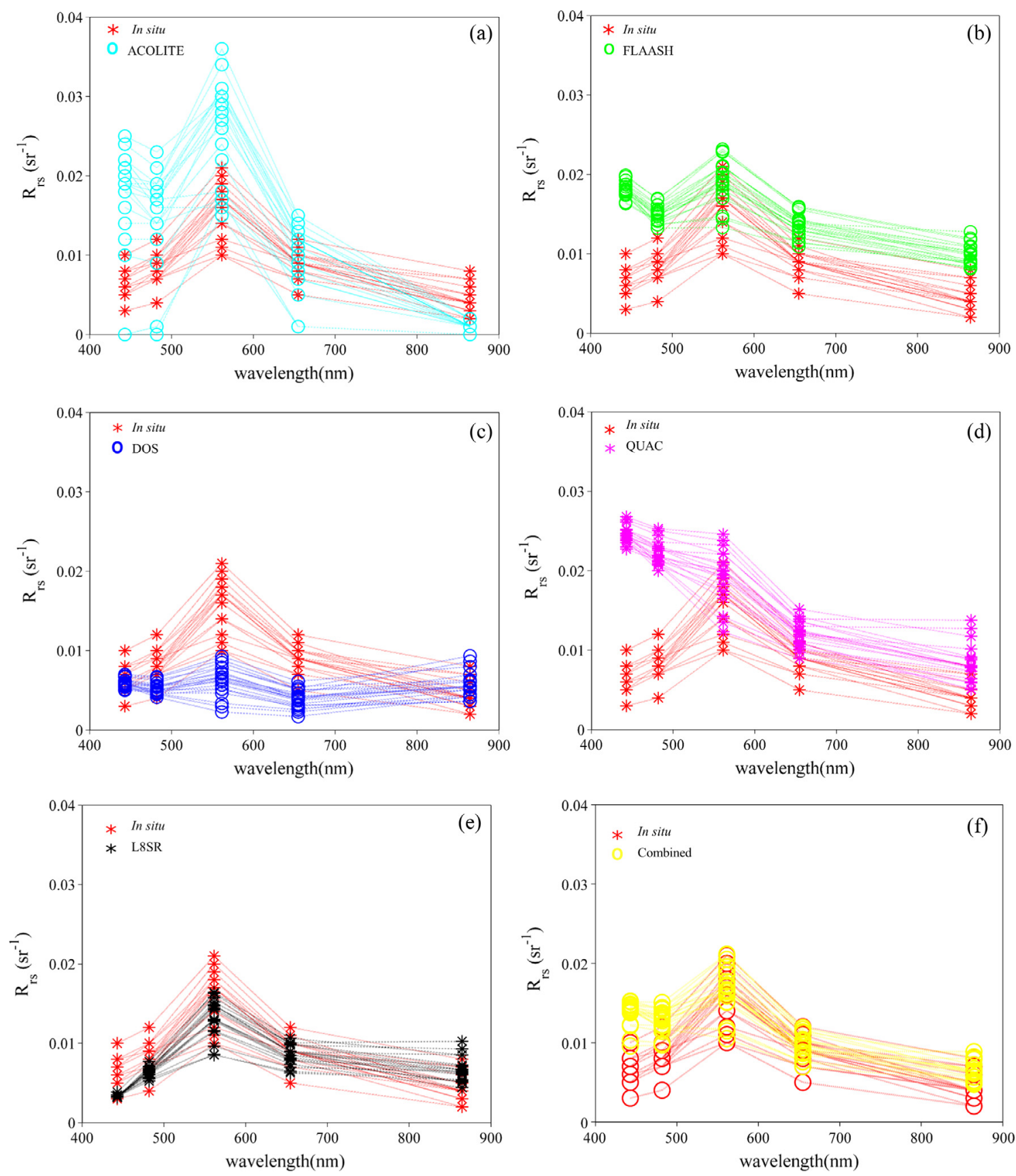

Fig. 3. Comparison of $R_{r s}$ between in situ measurements and atmospherically corrected OLI image (acquired on 13 October 2014) via ACOLITE (a), FLAASH (b), DOS (c), QUAC (d), L8SR (e); combined AC methods (f); in the visible-NIR OLI bands considering all the sampling spots. It is worth to note that the behavior between the OLI central wavelengths were not predicted, the lines were used just to link the OLI values.

Table 3

Error analysis of $R_{r s}$ retrieved from each atmospheric correction (AC) method and the combined AC methods. The Mean Absolute Percentage Error (Eq. (3), in \%) and Bias (Eq. (4), in $\mathrm{mg} \mathrm{L}^{-1}$ ) were calculated from each OLI band using $n=6$ sampling stations that matches with OLI overpass.

\begin{tabular}{|c|c|c|c|c|c|c|c|c|c|c|}
\hline \multirow[t]{2}{*}{ AC methods } & \multicolumn{5}{|c|}{ MAPE (in \%) } & \multicolumn{5}{|c|}{ BIAS (in $\mathrm{sr}^{-1}$ ) } \\
\hline & OLI1 & OLI2 & OLI3 & OLI4 & OLI5 & OLI1 & OLI2 & OLI3 & OLI4 & OLI5 \\
\hline ACOLITE & 99.10 & 65.47 & 33.98 & 43.91 & 86.99 & $-2.6 \mathrm{E}-03$ & $-9.2 \mathrm{E}-05$ & $-5.4 \mathrm{E}-03$ & $3.7 \mathrm{E}-03$ & $5.1 \mathrm{E}-03$ \\
\hline FLAASH & 131.87 & 51.73 & 9.61 & 33.38 & 81.71 & $-1.0 \mathrm{E}-02$ & $-5.1 \mathrm{E}-03$ & $-1.7 \mathrm{E}-03$ & $-3.4 \mathrm{E}-03$ & $-4.8 \mathrm{E}-03$ \\
\hline QUAC & 215.59 & 126.56 & 12.39 & 22.46 & 74.99 & $-5.3 \mathrm{E}-04$ & $-1.0 \mathrm{E}-03$ & $9.0 \mathrm{E}-04$ & $-1.6 \mathrm{E}-03$ & $-4.3 \mathrm{E}-03$ \\
\hline L8SR & 18.29 & 14.67 & 6.39 & 16.70 & 72.80 & $-1.6 \mathrm{E}-02$ & $-1.2 \mathrm{E}-02$ & $-2.1 \mathrm{E}-03$ & $-2.3 \mathrm{E}-03$ & $-4.2 \mathrm{E}-03$ \\
\hline Combined & 59.70 & 20.91 & 9.30 & 12.74 & 38.89 & $-4.5 \mathrm{E}-03$ & $-1.9 \mathrm{E}-03$ & $1.3 \mathrm{E}-03$ & $9.5 \mathrm{E}-04$ & $-1.4 \mathrm{E}-03$ \\
\hline
\end{tabular}

Bold numbers represent the best result, it means, the lowest errors among all analysis. 
negative Bias for OLI1, OLI2 and OLI3 bands and positive values for OLI4 and OLI5 bands). DOS exhibited the low errors in OLI1 (MAPE $=29.01 \%$ ) but it did not work well in OLI3 $(\mathrm{MAPE}=62.23 \%)$ and OLI4 $(\mathrm{MAPE}=58.02 \%)$, as observed in Fig. 4c. The L8SR product (Fig. 4e) retrieved similar $R^{2}$ to other AC methods and provide good estimates of $R_{r s}$, mainly in OLI4 band (MAPE $=6.39 \%$ ). The combination of all atmospheric correction methods by averaging the results from each AC method, represented in Table 3 by the Combined results, provided lower MAPE and Bias than most AC methods, excepted for L8SR. However, it is important to highlight that the lowest errors for OLI4 and OLI5 were resulted from the Combined method (Fig. 4k) the points spread out near the 1:1 line. Among all tested methods, the L8SR product achieved the lowest errors for OLI1, OLI2, and OLI3 spectral bands.

Considering remote-sensed applications, the Coastal (OLI1) and Blue (OLI2) spectral regions are used to provide atmospheric information and to estimate colored dissolved organic matter concentrations (Roy et al., 2014). OLI3, OLI4 and OLI5 bands are the spectral ranges most used to estimate TSM concentrations. Based on such information, the optical closure from OLI3, OLI4 and OLI5 bands was analyzed by calculating of $R^{2}$ (Fig. 4). In order to evaluate the temporal influence in our dataset, two datasets were considered to calculate the $R^{2}$ : (1) considering only 6 sampling stations (that matched with OLI overpass, Fig. 4, left); and (2) considering 18 sampling stations (all dataset from the second fieldwork, Fig. 4, right). The results show $R^{2}$ higher than $60 \%$ (except DOS with 6 stations) in both datasets $\left(R^{2}\right.$ ACOLITE $=0.81$ and 0.61 ; $R_{D O S}^{2}=0.02$ and $0.71 ; \quad R_{F L A A S H}^{2}=0.91$ and 0.76 ; $R_{Q U A C}^{2}=0.83 \quad$ and $0.76 ; \quad R_{L 8 S R}^{2}=0.80 \quad$ and 0.72 ; $R_{\text {COMBINED }}^{2}=0.89$ and 0.76 ).

\subsection{TSM bio-optical model - calibration and validation}

The TSM retrieval models were calibrated and validated using $R_{r s \_s}$ for OLI spectral bands (see Section 2.6). Model parameters and error analyses are displayed in Table 4 . The single-band model using the OLI5 band and quadratic fit exhibited the best performance (nRMSE of $12.69 \%$ and bias of $1.82 \mathrm{mg} \mathrm{L}^{-1}$ ), whereas, model using the OLI3 band and the exponential adjustment exhibited the poorest performance (nRMSE of $21.34 \%$ and bias of $6.05 \mathrm{mg} \mathrm{L}^{-1}$ ). The best results from band ratio model are also shown in Table 4 (nRMSE were $35.22 \%$ and $30.20 \%$ for OLI5/ OLI2 and OLI5/OLI4, respectively), however, the singleband model provided TSM concentrations with better accuracy.

The RMSE from linear and quadratic adjustments for single-band model are quite similar for each band, hence, a residual analysis ( $F$-test) was carried out to evaluate if the errors showed equal variances taking into account a $99 \%$ confidence level. $F$-test results indicated that there is no evidence to reject the null hypothesis $\left(F_{\text {Green }}=1.5012\right.$; $F_{\text {Red }}=1.0014 ; F_{N I R}=1.0890$, and $\left.F_{\text {critical }}=4.155\right)$, which confirms that the outcomes presented equal variances, independent of spectral band or adjustments. The quadratic fitting, due to slightly higher $R^{2}$ than linear fitting, was applied to AC scene using the OLI3, OLI4 and OLI5 bands (Eqs. (7), (8), and (9), respectively).

$$
\begin{aligned}
\mathrm{TSM} & =48703 \times(O L I 3)^{2}+771.04 \times(O L I 3)-1.24 \\
\mathrm{TSM} & =274555 \times(O L I 4)^{2}-150.78 \times(O L I 4)+2.27 \\
\mathrm{TSM} & =242797 \times(O L I 5)^{2}+2568.4 \times(O L I 5)+4.22
\end{aligned}
$$

\subsection{Atmospheric correction assessment via TSM estimates}

The error analysis between in situ TSM concentrations and estimated TSM concentrations (via application of Eqs. (7)-(9) to OLI image corrected using ACOLITE, DOS, FLAASH, QUAC, L8SR and Combined AC were made (Table 5). The RMSE ranged from $2.28 \mathrm{mg} \mathrm{L}^{-1}$ to $31.98 \mathrm{mg} \mathrm{L}^{-1}$, the MAPE ranged from $7.71 \%$ to $128.45 \%$, and the Bias was between $-17.17 \mathrm{mg} \mathrm{L}^{-1}$ and $29.23 \mathrm{mg} \mathrm{L}^{-1}$.

The best performance of AC method was the L8SR product, with a MAPE of almost $10 \%$ using OLI3 for TSM estimates. For OLI4, the best performances were yielded by L8SR $(\mathrm{MAPE}=12.95 \%)$ and by combined $(\mathrm{MAPE}=12.66 \%)$. Regarding on OLI5, the lowest error was obtained by DOS (MAPE $=57.52 \%)$, even with improvements to provide $R_{r s}$ from Combined method see Table 3), the errors for OLI5 was higher $(\mathrm{MAPE}=63.44 \%)$. The lowest MAPE values showed the suitability of L8SR for OLI3 and OLI4 to retrieve the TSM concentrations.

\section{Discussion}

The water-leaving radiance is resulted from interaction between the irradiance that reaches an aquatic system and the water molecules and OSCs present within water. High TSM concentrations saturate remotely sensed signal for all wavelengths. In visible and NIR regions, a linear relationship can be found between TSM concentrations and radiances or reflectances, however, a quadratic relationship can appear if the TSM concentration increases more than $50 \mathrm{mg} \mathrm{L}^{-1}$ (Reza, 2008; Ritchie et al., 1990). Based on TSM concentrations found in the BBHR, the linear and quadratic relationships with OLI bands showed good results to provide the TSM retrieval models. The best model performance for BBHR was found for the OLI5 using the quadratic relationship (see Table 4, MAPE $=12.69 \%$ ). The NIR region is predominantly affected by the water absorption and the scattering of suspended matter, which might be enough to ensure the spectral feature found in such interval (Binding et al., 2010).

However, scattering and absorption processes caused by molecules and gases present in atmosphere affect the spectral shape and magnitude of spectral curves registered 

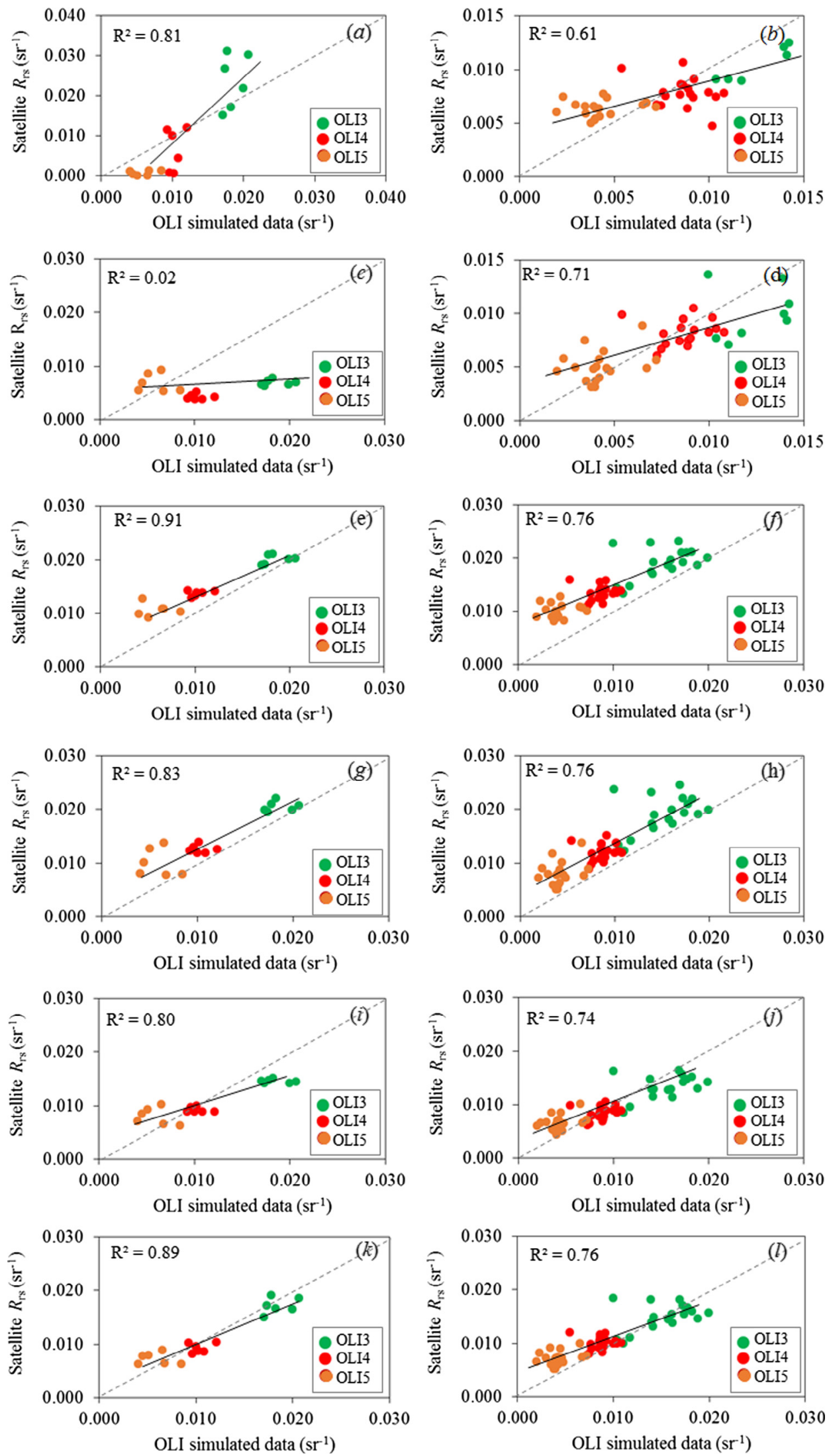

Fig. 4. Matching using 6 samples (left) and 18 samples (right) among $R_{r s}$ from resampled and atmospherically corrected image for each AC method - (a and b) ACOLITE; (c and d) DOS; (e and f) FLAASH; (g and h) QUAC; (i and j) L8SR; and (k and l) combined. Solid line represents the fit between datasets and dotted line represents $x=y$ line. 
Table 4

TSM retrieval models by OLI simulated data with respective adjustments (linear, exponential, and quadratic) and the coefficients $(a, b, c)$, and errors analysis using RMSE $\left(\mathrm{mg} \mathrm{L}^{-1}\right)$, $\mathrm{nRMSE}(\%)$, Bias $\left(\mathrm{mg} \mathrm{L}^{-1}\right)$, and $R^{2}$ where Linear: $\mathrm{TSM}=a \times R_{r s}+b$; $\operatorname{Exponential:~} \operatorname{TSM}=y=a \times \exp \left(b \times R_{r s}\right)$; and Quadratic: TSM $=a \times\left(R_{r s}{ }^{2}\right)+b \times R_{r s}+c$.

\begin{tabular}{|c|c|c|c|c|c|c|c|c|c|}
\hline Index & Fitting & $p$-value & $a$ & $b$ & $c$ & $\operatorname{RMSE}\left(\mathrm{mg} \mathrm{L}^{-1}\right)$ & nRMSE (in \%) & $\operatorname{Bias}\left(\mathrm{mg} \mathrm{L}^{-1}\right)$ & $R^{2}$ \\
\hline \multirow[t]{3}{*}{ OLI3 } & Linear & $<0.01$ & 1995.8 & -8.13 & - & 4.93 & 17.42 & 2.61 & 0.65 \\
\hline & Exponential & $<0.01$ & 2.31 & 142.04 & - & 6.05 & 21.34 & 3.69 & 0.62 \\
\hline & Quadratic & $<0.01$ & 48,703 & 771.04 & -1.24 & 5.04 & 17.82 & 3.19 & 0.65 \\
\hline \multirow[t]{3}{*}{ OLI4 } & Linear & $<0.01$ & 3814.7 & -10.75 & - & 4.45 & 15.74 & 1.51 & 0.69 \\
\hline & Exponential & $<0.01$ & 1.94 & 270.15 & - & 5.18 & 18.31 & 2.40 & 0.66 \\
\hline & Quadratic & $<0.01$ & 274,555 & -150.78 & 2.27 & 4.58 & 16.17 & 2.40 & 0.71 \\
\hline \multirow[t]{3}{*}{ OLI5 } & Linear & $<0.01$ & 4495.5 & 1.41 & - & 3.34 & 11.82 & 1.63 & 0.65 \\
\hline & Exponential & $<0.01$ & 4.99 & 288.05 & - & 4.66 & 16.47 & 1.26 & 0.51 \\
\hline & Quadratic & $<0.01$ & 242,797 & 2568.4 & 4.22 & 3.59 & 12.69 & 1.82 & 0.67 \\
\hline OLI5/OLI2 & Linear & $<0.01$ & 31.91 & -0.43 & - & 7.44 & 26.32 & -0.98 & 0.25 \\
\hline OLI5/OLI4 & Linear & $<0.01$ & 38.34 & -1.37 & - & 6.39 & 30.89 & 2.17 & 0.32 \\
\hline
\end{tabular}

Bold numbers represent the best result, it means, the lowest errors among all analysis.

Table 5

Error analyses of TSM estimates from AC OLI images using RMSE (in $\mathrm{mg} \mathrm{L}^{-1}$ ), MAPE (\%), and Bias (mg L $\mathrm{L}^{-1}$ ). The quadratic TSM retrieval models (Eqs. (7)-(9)) were applied to each atmospherically corrected OLI3, OLI4 and OLI5 bands.

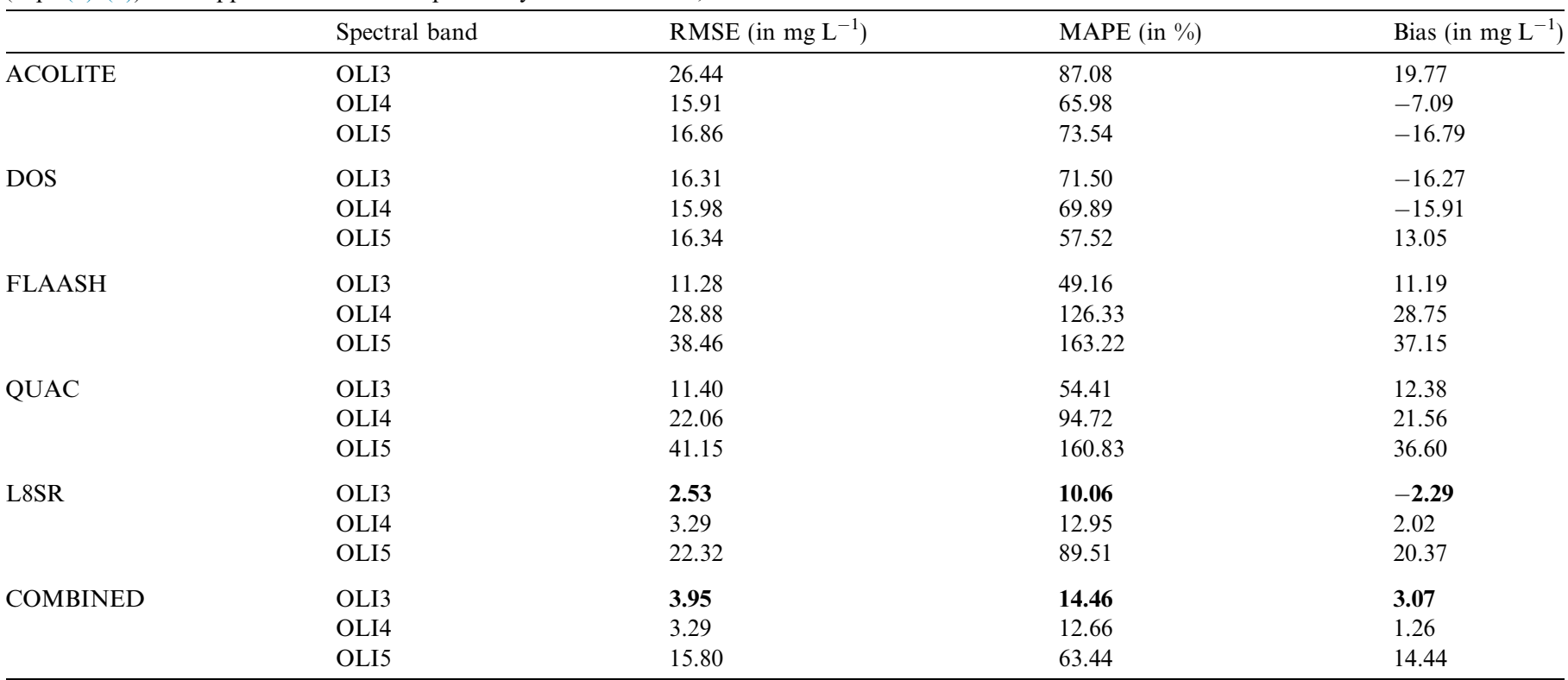

Bold numbers represent the best result, it means, the lowest errors among all analysis.

by remote sensors. Even with AC method applications, the minimum residual still remains in AC images. Furthermore, when information about atmospheric conditions are not available, some assumptions required might be made to apply the atmospheric correction, which can introduce errors in $R_{r s}$ estimated from images.

FLAASH (Fig. 3b) retrieved reliable values of $R_{r s}$ when compared to reference data, except in OLI1. The circles along the 1:1 line in Fig. 4e and $\mathrm{f}$ confirm the suitability of $R_{r s}$ in OLI3, OLI4 and OLI5. The FLAASH's accuracy can be a consequence of using Cirrus spectral band as input to detect clouds and water vapor content that were not noticeable in other bands (Watanabe et al., 2015).
However, the suitability of FLAASH was not demonstrated when TSM retrieval model was applied to FLAASH's image, since it provided a MAPE of $49 \%$ for OLI3 (see Table 4). Furthermore, the retrieved $R_{r s}$ in OLI1 (Fig. 3b) indicated that the scattering contribution of aerosols was not well modeled by MODTRAN when it was used the 'Rural model' setting as recommended by ENVI (2009). QUAC retrieved spectral curves similar to FLAASH, however QUAC made the correction in a faster way without spectral band requirement, however, some approximations did not accurately calculate the scattering effect at shorter wavelengths. The automatic selection of end-members made by QUAC did not allow identifying 

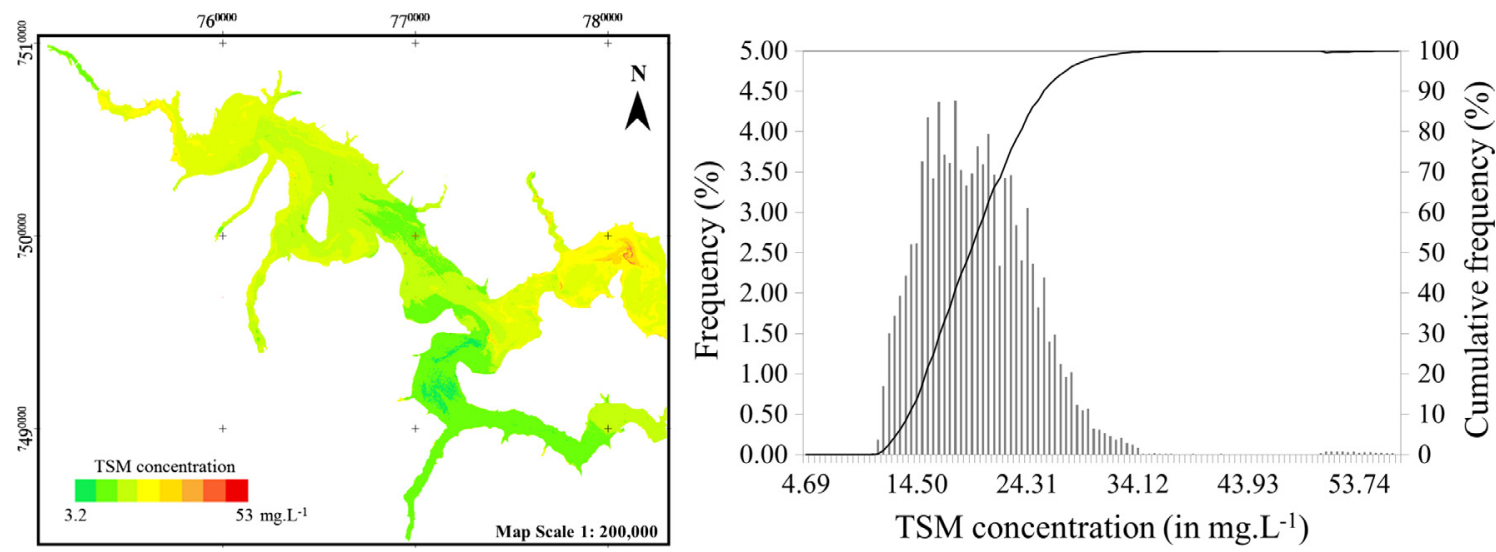

Fig. 5. TSM concentration retrieval using the OLI3 band and quadratic model applied to the L8SR atmospherically corrected image and its respective TSM frequency histogram.

which targets were selected to compute the end-member spectra and remove atmospheric effects, which did not model efficiently the aerosol scattering at shorter wavelengths.

The ACOLITE (Fig. 3a) and DOS (Fig. 3c) method did not produce reliable $R_{r s}$ estimates for OLI3 and OLI4. Although the results presented a similar spectral shape to the reference data, the magnitude of all spectral curves were not similar to the reference data. These results demonstrated a constraint in applying such methods to images that cover other aquatic systems with the same TSM levels, which can be resulted from the contribution of aerosol estimates using the SWIR settings. The ACOLITE was developed for turbid waters, and the BBHR can be considered as moderate system, i.e., with TSM concentrations about $30 \mathrm{mg} \mathrm{L}^{-1}$ (Vanhellemont and Ruddick, 2015), and for such reason ACOLITE can have underestimated the aerosol contribution and overestimated the $R_{r s}$ values. DOS was the simplest approach that aimed to minimize the additive atmospheric effect from remote image by subtracting the minimum value found in the histogram (Chavez, 1988). However, the minimum value identified in each band is strongly dependent on quantity and composition of TSM concentration present within the aquatic system. Other effects, such as specular reflection and whitecaps (Gong et al., 2008), also affect the minimum value assumed for a black pixel. In the BBHR, maybe we cannot to consider the "blackpixel" assumption since the reflectance in OLI3 or OLI4 are high due to high levels of Chl- $a$ or other OSCs with high reflectances in those spectral regions. Therefore, the minimum values for OLI3 and OLI4 could imply in an overestimation of additive effect and result in low values of $R_{r s}$ after the subtraction.

The L8SR product achieved the lowest TSM retrieval errors, since the quadratic model using OLI3 spectral band retrieved an MAPE of $10 \%$, and an RMSE of $2.53 \mathrm{mg} \mathrm{L}^{-1}$, approximately. Furthermore, analyzing the L8SR results, the best agreement between $R_{r s}$ from satellite and $R_{r s \_s}$ (used as reference data) occurred in OLI4, where the circles were along the dashed line (Fig. $4 i$ and $j$ ). The high positive correlation found in OLI4 indicated by the relation between the reflectances and gross particulate scattering, which increases the values of $R_{r s}$ in the red and NIR spectral region (Matthew, 2011) and it can explain the low MAPE retrieved $(12.95 \%$ - Table 5). The Provisional Landsat 8 Surface Reflectance Code (LaSRC) (Fig. 3e) provided reliable $R_{r s}$ for all OLI bands. The LaSRC is based on Second Simulation of the Satellite Signal in the Solar Spectrum Vectorial (6SV) model and the inputs for each scene are the ancillary data from MODIS CMA, such as temperature, water vapor and aerosol optical thickness, which improves the suitability of retrieved $R_{r s}$ via L8SR (Vermote et al., 2016).

The most challenge in atmospheric correction applications was to retrieve $R_{r s}$ from OLI5. OLI5 is affected by $a_{w}$, which can be responsible for attenuating almost $75 \%$ of light at $709 \mathrm{~nm}$ in the BBHR (Watanabe et al., 2016), and even with a combined AC method that improved $R_{r s}$ estimates in that band, the error was relatively high (MAPE $=38.89 \%$ ) when compared to the other OLI bands. The poorest results in OLI5 from all atmospheric correction methods demonstrated that none AC method was able to provide suitable $R_{r s}$ in such spectral region, which implied in poor TSM estimates even with the best in situ TSM model (nRMSE reached $12.69 \%$ with in situ measurements, see Table 4). This showed that successfully TSM estimates are strongly linked to the suitability of atmospheric correction methods to retrieve the $R_{r s}$. The atmospheric correction models attempt to compute the atmospheric contribution in the NIR region, however, the $R_{r s}$ is extremely influenced by the OSC composition within water and absorption by itself.

Based on error analysis, we chose to apply the quadratic model to the OLI3 band (Eq. (7)) by using L8SR algorithm. The TSM concentration spatial distribution can be observed in Fig. 5, where we demonstrated the TSM estimates ranged from $3.24 \mathrm{mg} \mathrm{L}^{-1}$ to $52.28 \mathrm{mg} \mathrm{L}^{-1}$. 


\section{Conclusions}

The present study tested several atmospheric correction methods - ACOLITE, DOS, FLAASH, QUAC and L8SR, applied to inland water. The TSM retrieval errors from AC image were computed using different algorithms in order to demonstrate the relevance of testing the available atmospheric correction methods before using it in water color applications. Considering the achieved errors of TSM predictions, the best performance was exhibited by the OLI3 for L8SR, which produced low discrepancies among tested atmospheric correction methods. Furthermore, the OLI4 from L8SR data also presented a good result. Other atmospheric correction algorithms, such as FLAASH could retrieve better TSM estimates if there were available in situ information about atmospheric conditions. All atmospheric correction method tested failed in retrieving reliable $R_{r s}$ values for OLI5, since a slight over or underestimation in this region implied on high TSM retrieval errors. Such conclusion remains as a challenge to overcome in the future works.

Although this study evaluated several methods applied to a unique inland water body, the conclusions remarked here are applicable for all inland water systems that deal with atmospheric correction applications. The present work verified that atmospheric correction plays an important role in TSM retrieval errors, and because of that, atmospheric correction algorithms should be tested before their application to map TSM distributions, or other OSCs, in order to minimize the atmospheric interferences that provide over or underestimation of OSCs.

\section{Acknowledgments}

The authors are very grateful to São Paulo Research Foundation (FAPESP Process $N^{\circ}$ 2012/19821-10 and 2015/21586-9), National Council for Scientific and Technological Development (CNPq Process No 400881/2013-6 and 472131/2012-5), and PPGCC/UNESP for financial support, and Coordination for the Improvement of Higher Education Personnel (CAPES) for scholarship funding.

\section{References}

Adler-Golden, S.M., Matthew, M.W., Bernstein, L.S., Levine, R.Y., Berk, A., Richtsmeier, S.C., Acharya, P.K., Anderson, G.P., Felde, J.W., Gardner, J.A., Goke, M.L., Jeong, L.S., Pukall, B., Ratkowski, A.J., Hsiao-Hua, K. B., 1999. Atmospheric correction for shortwave spectral imagery based on MODTRAN4. SPIE Proc. Imaging Spectrom. 3753, 61-69.

APHA, 1998. Standard Methods for the Examination of Water and Wastewater. American Public Health Association, Washington.

Barsi, J., Lee, K., Kvaran, G., Markham, L.B., Pedelty, J.A., 2014. The spectral response of the Landsat-8 Operational Land Imager. Rem. Sens. 6 (10), 10232-10251.

Baylei, S.W., Werdell, P.J., 2006. A multi-sensor approach for the on-orbit validation of ocean color satellite data products. Rem. Sens. Environ. $102(1-2), 12-23$

Bernardo, N.M.R., Alcântara, E., Watanabe, F., Rodrigues, T., Imai, N., Curtarelli, M., Barbosa, C., 2015. Bio-optical model tuning for retrieving the total suspended matter concentration in Barra Bonita Reservoir. Rev. Bras. Cartogr. 67 (7), 1497-1507 (in English).

Bernardo, N.M.R., Watanabe, F., Rodrigues, T., Alcântara, E., 2016. Evaluation of the suitability of MODIS, OLCI, and OLI for mapping the distribution of total suspended matter in the Barra Bonita Reservoir (Tietê River, Brazil). Rem. Sens. Appl.: Soc. Environ. 4, 68-82.

Bernstein, L.S., 2005. Validation of the QUick Atmospheric Correction (QUAC) algorithm for VNIR-SWIR multi- and hyperspectral imagery. In: SPIE Proceedings, Algorithms and Technologies for Multispectral, Hyperspectral, and Ultraspectral Imagery XI, 5806, pp. 668-678.

Bernstein, L.S., Jin, X., Gregor, B., Adler-Golden, S.M., 2013. Quick atmospheric correction code: algorithm description and recent upgrades. Opt. Eng. 51 (11), 111719-1-111719-11.

Berk, A., Bernstei, L.S., Anderson, G.P., Acharya, P.K., Roberston, D.C., Chetwynd, J.H., Adler-Golden, S.M., 1998. MODTRAN cloud and multiple scattering upgrades with application to AVIRIS. Rem. Sens. Environ. 65 (3), 367-375.

Binding, C.E., Jerome, J.H., Bukata, R.P., Booty, W.G., 2010. Suspended particles matter in Lake Erie derived from MODIS aquatic colour imagery. Int. J. Rem. Sens. 31 (10), 5239-5255.

Bonansea, M., Ledesma, C., Rodriguez, C., Pinotti, L., Antunes, M.H., 2015. Effects of atmospheric correction of landsat in water clarity assessment. Adv. Space Res. 56, 2345-2355.

Chavez Jr., P.S., 1988. An improved dark-object substraction technique for atmospheric scattering correction of multispectral data. Rem. Sens. Environ. 24, 459-479.

Dellamano-Oliveira, M.J., Vieira, A.A.H., Rocha, O., Colombo, V., 2008. Phytoplankton taxonomic composition and temporal changes in a tropical reservoir. Fundam. Appl. Limnol. 171, 27-38.

ENVI, 2009. Atmospheric Correction Module. QUAC and FLAASH User's Guide. ITT Visual Information Solutions, Boulder, CO.

Fondriest Environmental, Inc., 2013. "Dissolved Oxygen" Fundamentals of Environmental Measurements Available at: $<$ http://www.fondriest.com/environmental-measurements/parameters/water-quality/dissolved-oxygen $/>$.

Golterman, H.L., 1975. Developments in water science 2. In: Physiological Limnology: An Approach to the Physiology of Lake Ecosystems. Elsevier, Amsterdam, The Netherlands.

Gong, S., Huang, J., Li, Y., Wang, H., 2008. Comparison of atmospheric correction algorithms for TM image in inland waters. Int. J. Rem. Sens. 29 (8), 2199-2210.

Goyens, C., Jamet, C., Schroeder, T., 2013. Evaluation of four atmospheric correction algorithms for MODIS-Aqua images over contrasted coastal waters. Rem. Sens. Environ. 131, 63-75.

Ha, N.T.T., Koike, K., Nhuan, M.T., 2014. Improved accuracy of chlorophyll-a concentration estimates from MODIS imagery using a two-band ratio algorithm and geostatistics: as applied to the monitoring of eutrophication processes over Tien Yen Bay (Northern Vietnam). Rem. Sens. 6 (1), 421-442.

Hadjimitsis, D.G., Clayton, C., 2009. Assessment of temporal variations of water quality in inland water bodies using atmospheric corrected satellite remotely sensed image data. Environ. Monit. Assess. 159 (14), 281-292.

He, Q., Chen, C., 2014. A new approach for atmospheric correction of MODIS imagery in turbid coastal waters: a case study for the Pearl River Estuary. Rem. Sens. Lett. 5 (3), 249-257.

Kutser, T., Paavel, B., Verpoorter, C., Ligi, M., Soomets, T., Toming, K., Casal, G., 2016. Remote sensing of black lakes using 810 reflectance peak for retrieving water quality parameters of optically complex waters. Rem. Sens. 8, 497-512.

Lobo, F.L., Costa, M.P.F., Novo, E.M.L.M., 2014. Time-series analysis of Landsat-MSS/TM/OLI images over Amazonian waters impacted by gold mining activities. Rem. Sens. Environ. 157, 170-184.

Matthew, M.W., Adler-Golden, S.M., Berk, A., Richtsmeier, S.C., Levine, R.Y., Bernstein, L.S., Acharya, P.K., Anderson, G.P., Felde, G.W., Hoke, M.P., Ratkowski, A., Burke, H.-H., Kaiser, R.D., Miller, D.P., 
2000. Status of atmospheric correction using a MODTRAN4-based algorithm. In: SPIE Proceedings, Algorithms for Multispectral, Hyperspectral, and Ultraspectral Imagery, VI, 4049, pp. 199-207.

Matthew, M.W., 2011. A current review of empirical models procedures of remote sensing in inland and near-coastal transitional waters. Int. J. Rem. Sens. 32 (21), 6855-6899.

Mobley, C.D., 1999. Estimation of the remote-sensing reflectance from above-surface measurements. Appl. Opt. 38 (36), 7442-7455.

Moses, W.J., Gitelson, A.A., Povazhnyy, V., 2009. Estimation of chlorophyll- $a$ concentration in case II waters using MODIS and MERIS data - successes and challenges. Environ. Res. Lett. 4, 1-8.

Moses, W.J., Gitelson, A.A., Perk, R.L., Gurlin, D., Rundquist, D.C., Leavitt, B.C., Barrow, T.M., Brakhage, P., 2012. Estimation of chlorophyll-a concentration in turbid productive waters using airborne hyperspectral data. Water Res. 46 (4), 993-1004.

Neukermans, G., Ruddick, K., Bernard, E., Ramon, D., Nechad, B., Deschamps, P.-Y., 2009. Mapping total suspended matter from geostationary satellites: a feasibility study with SEVIRI in the Southern North Sea. Opt. Express 17 (16), 14029-14052.

Petesse, M.L., Petrere Jr., M., Spigolon, R.J., 2007. The hydraulic management of the Barra Bonita reservoir (SP, Brazil) as a factor influencing the temporal succession of its fish community. Braz. J. Biol. 67 (3), 433-445.

Reza, M., 2008. Assessment of suspended sediments concentration in surface waters, using MODIS images. Am. J. Appl. Sci. 5 (7), 798-804.

Ritchie, J., Cooper, C., Schiebe, F., 1990. The relationship of MSS and TM digital data with suspended sediments, chlorophyll, and temperature in Moon Lake, Mississippi. Rem. Sens. Environ. 33 (2), 137-148.

Richter, R., Schläpfer, D., 2016. Atmospheric/Topographic Correction for Satellite Imagery Technical Report. German Aerospace Center (DLR), Wessling, $194 \mathrm{p}$.

Rotta, L.H.S., Alcântara, E.H., Watanabe, F.S.Y., Rodrigues, T.W.P., Imai, N.N., 2016. Atmospheric correction assessment of SPOT- 6 image and its influence on models to estimate column transparency in tropical reservoir. Rem. Sens. Appl.: Soc. Environ. 4, 158-166.

Roy, D.P., Wulder, M.A., Loveland, T.R., Woodcock, C.E., Allen, R.G., Anderson, M.C., Helder, D., Irons, J.R., Johnson, D.M., Kennedy, R., Scambos, T.A., Schaaf, C.B., Schoot, J.R., Sheng, Y., Vermote, E. F., Belward, A.S., Bindschadler, R., Cohen, W.B., Gao, F., Hipple, J. D., Hostert, P., Huntington, C.O., Justice, C.O., Kilic, A., Kovalskyy, V., Lee, Z.P., Lymburner, L., Hostert, P., Masek, J., McCorkel, J., Shuai, Y., Trezza, R., Vogelmann, J., Wynne, R.H., Zhu, Z., 2014. Landsat-8: science and product vision for terrestrial global change research. Rem. Sens. Environ. 145, 154-172.

Ruddick, K.G., Ovidio, F., Rijkeboer, M., 2000. Atmospheric correction of SeaWiFS imagery for turbid coastal and inland waters. Appl. Opt. 39 (6), 897-912.

Rundquist, D.C., Han, L., Schalles, J.F., Peake, J.S., 1996. Remote measurement of algal chlorophyll in surface waters: the case for the first derivative of reflectance near $690 \mathrm{~nm}$. Photogram. Eng. Rem. Sens. 62, 195-200.

Smith, S.S., Espíndola, E.L.G., Rocha, O., 2014. Environmental gradient in reservoirs of the medium and low Tietê River: limnological differences trough the habitat sequence. Acta Limnol. Bras. 26 (1), $73-88$.

Song, C.H., Woodcock, C.D., Seto, K.C., Lenney, M.P., Macomber, S.A., 2001. Classification and change detection using Landsat TM data: when and how to correct atmospheric effects? Rem. Sens. Environ. 75, 230-244.

Stratoulias, D., Baltzer, H., Sykioti, O., Zlinszky, A., Tóth, V.R., 2015. Evaluating sentinel-2 for lakeshore habitat mapping based on airborne hyperspectral data. Sensors 15, 22956-22969.

Tkacik, D., Luna-Cruz, Y., Clinton, N., Spak, S., Ryan, J., 2012. Atmospheric correction for MASTER image data using localized modelled and observed meteorology and trace gases. Rem. Sens. Lett. 3 (3), 201-209.

TriOS Optical Sensors, 2009. Manual: msda_xe 8.5. TriOS, Oldenburg, Germany.

Tundisi, J.G., Matsumura-Tundisi, T., Abe, D.S., 2008. The ecological dynamics of Barra Bonita (Tietê River, SP, Brazil) reservoir: implications for its biodiversity. Braz. J. Biol. 68 (4), 1079-1098.

USGS, 2015a. Product Guide. Provisional Landsat 8 Surface Reflectance Product, v. 1.5.

USGS, 2015b. Landsat Processing Details. Standard Parameters. Available at: <http://landsat.usgs.gov/Landsat_Processing Details.php>.

Van der Meer, F., 1999. Physical principles of optical remote sensing. In: Stein, A., Van Der Meer, F., Gorte, B. (Eds.), Spatial Statistics for Remote Sensing. Kluwer Academic Publishers, Dordrecht, Netherlands (Chapter 3).

Vanhellemont, Q., Ruddick, K., 2015. Advantages of high quality SWIR bands for ocean colour processing: examples from Landsat-8. Rem. Sens. Environ. 161, 89-106.

Vanhellemont, Q., Ruddick, K., 2014. Turbid wakes associated with offshore wind turbines observed with Landsat 8. Remote Sens. Environ. 145, 105-115. http://dx.doi.org/10.1016/j.rse.2014.01.009.

Vermote, E., Kotchenova, S.Y., Ray, J.P., 2011. MODIS Surface Reflectance User's Guide.

Vermote, E., Tanré, D., Deuzé, J., Herman, M., Morcrette, J., Kotchenova, S., 2006. Second Simulation of a Satellite Signal in the Solar spectrum-vector (6SV). 6S User Guide Version 3.

Vermote, E.F., Vermeulen, A., 1999. Atmospheric Correction Algorithm: Spectral Reflectances (MOD09). Available at: $<$ https://modis.gsfc.nasa.gov/data/atbd/atbd_mod08.pdf>.

Vermote, E., Justice, C., Claverie, M., Franch, B., 2016. Preliminary analysis of the performance of the Landsat 8/OLI land surface reflectance product. Rem. Sens. Environ. 185, 46-56.

Watanabe, F.S.Y., Alcântara, E., Rodrigues, T.W.P., Imai, N.N., Barbosa, C.C.F.B., Rotta, L.H.S., 2015. Estimation of chlorophyll-a concentration and the trophic state of Barra Bonita hydroelectric reservoir using OLI/Landsat-8 images. Int. J. Environ. Publ. Health 12, 10391-10417.

Watanabe, F., Mishra, D.R., Astuti, I., Rodrigues, T., Alcântara, E., Imai, N., Barbosa, C., 2016. Parametrization and calibration of a quasi-analytical algorithm for tropical eutrophic waters. ISPRS J. Photogramm. Remote Sens. 121, 28-47.

Wu, G., Cui, L., Liu, L., Chen, F., Fei, T., Liu, Y., 2015. Statistical model development and estimation of suspended particulate matter with Landsat 8 OLI images of Dogting Lake, China. Int. J. Rem. Sens. 36, 343-360.

Zheng, Z., Li, Y., Guo, Y., Xu, Y., Liu, G., Du, C., 2015. Landsat-based long-term monitoring of total suspended matter concentration pattern change in the wet season for Dongting Lake, China. Rem. Sens. 7 , 13975-13999. 